Article

\title{
Neuroinvasion and Encephalitis Following Intranasal Inoculation of SARS-CoV-2 in K18-hACE2 Mice
}

\author{
Pratima Kumari ${ }^{\dagger}$, Hussin A. Rothan ${ }^{+} \mathbb{D}$, Janhavi P. Natekar ${ }^{\dagger}$, Shannon Stone ${ }^{\dagger}$, Heather Pathak, Philip G. Strate, \\ Komal Arora, Margo A. Brinton and Mukesh Kumar *iD
}

Citation: Kumari, P.; Rothan, H.A.; Natekar, J.P.; Stone, S.; Pathak, H.; Strate, P.G.; Arora, K.; Brinton, M.A.; Kumar, M. Neuroinvasion and Encephalitis Following Intranasal Inoculation of SARS-CoV-2 in K18-hACE2 Mice. Viruses 2021, 13, 132. https://doi.org/10.3390/v13010 132

Academic Editor: Andrew Davidson Received: 14 December 2020

Accepted: 12 January 2021

Published: 19 January 2021

Publisher's Note: MDPI stays neutral with regard to jurisdictional claims in published maps and institutional affiliations.

Copyright: (c) 2021 by the authors. Licensee MDPI, Basel, Switzerland. This article is an open access article distributed under the terms and conditions of the Creative Commons Attribution (CC BY) license (https:// creativecommons.org/licenses/by/ $4.0 /)$.
Department of Biology, College of Arts and Sciences, Georgia State University, Atlanta, GA 30303, USA; pkumari1@gsu.edu (P.K.); hrothan@gsu.edu (H.A.R.); jnatekar1@gsu.edu (J.P.N.); sstone12@gsu.edu (S.S.); hpathak1@gsu.edu (H.P.); pstrate1@gsu.edu (P.G.S.); karora@gsu.edu (K.A.); mbrinton@gsu.edu (M.A.B.)

* Correspondence: mkumar8@gsu.edu

+ These authors contributed equally to this work.

\begin{abstract}
Severe acute respiratory syndrome coronavirus-2 (SARS-CoV-2) infection can cause neurological disease in humans, but little is known about the pathogenesis of SARS-CoV-2 infection in the central nervous system (CNS). Herein, using K18-hACE2 mice, we demonstrate that SARS-CoV-2 neuroinvasion and encephalitis is associated with mortality in these mice. Intranasal infection of K18-hACE2 mice with $10^{5}$ plaque-forming units of SARS-CoV-2 resulted in $100 \%$ mortality by day 6 after infection. The highest virus titers in the lungs were observed on day 3 and declined on days 5 and 6 after infection. By contrast, very high levels of infectious virus were uniformly detected in the brains of all the animals on days 5 and 6 . Onset of severe disease in infected mice correlated with peak viral levels in the brain. SARS-CoV-2-infected mice exhibited encephalitis hallmarks characterized by production of cytokines and chemokines, leukocyte infiltration, hemorrhage and neuronal cell death. SARS-CoV-2 was also found to productively infect cells within the nasal turbinate, eye and olfactory bulb, suggesting SARS-CoV-2 entry into the brain by this route after intranasal infection. Our data indicate that direct infection of CNS cells together with the induced inflammatory response in the brain resulted in the severe disease observed in SARS-CoV-2-infected K18-hACE2 mice.
\end{abstract}

Keywords: SARS-CoV-2; COVID-19; K18-hACE2 mice; neuroinvasion; neuroinflammation; encephalitis

\section{Introduction}

Severe acute respiratory syndrome coronavirus-2 (SARS-CoV-2) infection in humans can cause pneumonia, acute respiratory distress syndrome, acute lung injury, cytokine storm syndrome and death $[1,2]$. Although SARS-CoV-2 infection primarily causes respiratory disease, some patients develop symptoms of neurological disease, such as headache, loss of taste and smell, ataxia, meningitis, cognitive dysfunction, memory loss, seizures and impaired consciousness [3-10]. SARS-CoV-2 infection also induces long-term neurological sequelae in at least one-third of human cases. Infection with other coronaviruses, such as mouse hepatitis virus (MHV) in mice and SARS-CoV-1 and Middle East Respiratory Syndrome (MERS) virus in humans, has been shown to cause neurological disease [11,12]. However, little is known about the pathophysiology of SARS-CoV-2-associated neurological disease in humans.

Central nervous system (CNS) cells that express the SARS-CoV-2 receptor angiotensinconverting enzyme 2 (ACE2) include neurons, glial cells and astrocytes [13,14]. ACE2 is expressed in multiple human brain areas, including the amygdala, cerebral cortex and brainstem, with the highest expression levels found in the pons and medulla oblongata in the brainstem that contain the medullary respiratory centers of the brain $[8,15]$. Several human autopsy reports have documented the presence of SARS-CoV-2 RNA in brain tissues $[16,17]$. Human iPSC-derived neural progenitor cells (NPCs) have been shown to be permissive to SARS-CoV-2 infection, and both viral proteins and infectious viral 
particle production were detected in neurospheres and brain organoids infected with SARS-CoV-2 $[18,19]$. Human autopsy reports have shown evidence of lymphocytic panencephalitis, meningitis and brainstem perivascular and interstitial inflammatory changes with neuronal loss in COVID-19 patients [20]. These data suggest that SARS-CoV-2 can productively infect human CNS cells [21]. However, the contributions of CNS cell infection and induced neuroinflammation to the pathogenesis of SARS-CoV-2-associated disease are not well understood.

Small animal models provide a means for studying the neurological complications associated with SARS-CoV-2 infection. K18-hACE2-transgenic mice were originally developed for the study of SARS-CoV-1 pathogenesis. hACE2 expression in K18-hACE2 transgenic mice is driven by the human cytokeratin 18 (K18) promoter. It was recently reported that intranasal inoculation with SARS-CoV-2 results in a rapidly fatal disease in K18-hACE2 mice [22-25]. These studies were focused on describing the acute lung injury in SARS-CoV-2-infected K18-hACE2 mice that was associated with high levels of inflammatory cytokines and accumulation of immune cells in the lungs [22-25]. In these published studies, neither infectious virus nor viral RNA was detected in the olfactory bulbs or brains of the majority of the infected animals, indicating restricted neurotropism of SARS-CoV-2 in K18-hACE2 mice. In the present study, we show that intranasal infection of six-week-old K18-hACE2 mice by SARS-CoV-2 can cause severe neurological disease, with the brain being a major target organ for infection by this route of infection, and neuroinflammation and neuronal death contributing to the infection-associated morbidity and mortality. The data also suggest that SARS-CoV-2 can be trafficked to the brain via the olfactory bulb with subsequent transneuronal spread, as has been reported for other coronaviruses [26,27].

\section{Materials and Methods}

\subsection{Mice}

Hemizygous K18-hACE2 mice were purchased from the Jackson Laboratory (Bar Harbor, ME). All the animal experiments were conducted in a certified Animal Biosafety Level 3 (ABSL-3) laboratory at Georgia State University (GSU). The protocol was approved by the GSU Institutional Animal Care and Use Committee (Protocol number A20044). Six-week-old hemizygous K18-hACE2 mice were infected with $10^{5}$ plaque-forming units (PFU) of SARS-CoV-2 strain USA-WA1/2020 under ABSL-3 containment by intranasal inoculation. SARS-CoV-2 (USA-WA1/2020) was isolated from an oropharyngeal swab from a patient in Washington, USA (BEI NR-52281) [28]. Animals in the control group received equivalent amounts of sterile PBS via the same route. Roughly equal numbers of male and female mice were used. Animals were weighed and their appetite, activity, breathing and neurological signs assessed twice daily [29,30]. Mice that met the human endpoint criteria were euthanized to limit suffering. In independent experiments, mice were inoculated with PBS (Mock) or SARS-CoV-2 intranasally, and on days 1, 3, 5 and 6 after infection, animals were anesthetized using isoflurane and perfused with cold PBS; then, respiratory (nasal turbinate and lung) and other tissues (spleen, heart, liver, kidney, pancreas, eye, olfactory bulb and brain) were collected and flash frozen in 2-methylbutane (Sigma, St. Louis, MO, USA) [31-33]. Alternatively, mice were perfused with PBS followed by $4 \%$ paraformaldehyde (PFA), and tissues were harvested and cryoprotected in $30 \%$ sucrose (Sigma, St. Louis, MO, USA), and embedded in optimum cutting temperature (OCT) as described previously [31,34].

\subsection{Quantification of the Virus Load}

The virus titers were analyzed in the tissues by plaque assay and quantitative real-time PCR (qRT-PCR) [28,29]. Briefly, frozen tissues were weighed and homogenized in a bullet blender (Next Advance, Averill Park, NY, USA) using glass or zirconium oxide beads. Virus titers in tissue homogenates were measured by plaque assay using Vero cells. Quantitative RT-PCR was used to measure viral RNA levels with primers and probes specific for the SARS-CoV-2 N gene as described previously [28]. Viral genome copies were determined 
by comparison to a standard curve generated using a known amount of RNA extracted from previously titrated SARS-CoV-2 samples. Frozen tissues harvested from mock and infected animals were weighed and lysed in RLT buffer (Qiagen), and RNA was extracted using a Qiagen RNeasy Mini kit (Qiagen, Germantown, MD, USA). Total RNA extracted from the tissues was quantified and normalized, and viral RNA levels per $\mu g$ of total RNA were calculated.

\subsection{Measurement of Cytokines, Chemokines and Interferons}

The levels of mRNA for select cytokines/chemokines (IL-1 $\beta$, IL-6, TNF- $\alpha$, IFN- $\gamma$, CCL2 and CCL3) and interferon- $\alpha$ (IFN- $\alpha$ ) were determined in total RNA extracted from the lungs and brain using qRT-PCR. The fold change in infected tissues compared to mock tissues was calculated after normalizing to the GAPDH gene [31,34]. The primer sequences used for qRT-PCR are listed in Table 1. The protein levels of IFN- $\alpha$ were measured in the lung and brain homogenates using an ELISA kit (PBL Interferon Source, Piscataway, NJ, USA) $[29,30]$.

Table 1. Primer sequences used for qRT-PCR.

\begin{tabular}{|c|c|}
\hline Gene (Accession No.) & Primer Sequence $\left(5^{\prime}-3^{\prime}\right)$ \\
\hline \multicolumn{2}{|l|}{ IL-1 $\beta$ (NM_000576) } \\
\hline Forward & AGCACСТTCTTTCССТTCATC \\
\hline Reverse & GGACCAGACATCACCAAGC \\
\hline \multicolumn{2}{|l|}{ IL-6 (NM_000600) } \\
\hline Forward & CCAGGAGCCCAGCTATGAAC \\
\hline Reverse & CCCAGGGAGAAGGCAACTG \\
\hline \multicolumn{2}{|l|}{ CCL3 (NM_011337) } \\
\hline Forward & ATTCCACGCCAATTCATC \\
\hline Reverse & ATTCAGTTCCAGGTCAGT \\
\hline \multicolumn{2}{|l|}{ IFN- $\alpha$ (NM_010502) } \\
\hline Forward & CTCTGTGCTTTCCTGATG \\
\hline Reverse & CTGAGGTTATGAGTCTGAG \\
\hline \multicolumn{2}{|l|}{ TNF- $\alpha$ (NM_013693) } \\
\hline Forward & CCAGTCTGTATCCTTCTAA \\
\hline Reverse & TCTTGTGTTTCTGAGTAGT \\
\hline \multicolumn{2}{|l|}{ CCL2 (NM_011333) } \\
\hline Forward & TCACCTGCTGCTACTCATTCACCA \\
\hline Reverse & TACAGCTTCTTTGGGACACCTGCT \\
\hline \multicolumn{2}{|l|}{ IFN- $\gamma$ (NM_008337) } \\
\hline Forward & TTCACTGACCAATAAGAAAC \\
\hline Reverse & TACTACCTGACACATTCG \\
\hline
\end{tabular}

\subsection{Immunohistochemistry}

Sagittal sections (10- $\mu \mathrm{m}$ thick) were cut from the hemibrain tissues frozen in OCT. Tissue sections were stained with hematoxylin and eosin (H\&E) for histopathological evaluation [34,35]. Additionally, tissue sections were incubated with anti-CD45, antiNeuN and anti-SARS-CoV-2 spike protein antibodies (Thermo Fisher Scientific, Norcross, GA, USA) overnight at $4{ }^{\circ} \mathrm{C}$, followed by incubation with Alexa Fluor 546- or Alexa Fluor 488-conjugated secondary antibody for $1 \mathrm{~h}$ at room temperature [31,34]. Terminal deoxynucleotidyl transferase (dUTP) nick end labeling (TUNEL) staining was conducted 
using an in situ cell death detection kit (Roche, Indianapolis, Indiana, United States) as per the manufacturer's instructions [31,34]. Images were acquired using the Invitrogen ${ }^{\mathrm{TM}}$ EVOS $^{\text {тм M}}$ M000 Cell Imaging System (Thermo Fisher Scientific, Norcross, GA, USA).

\subsection{Statistical Analysis}

An unpaired Student's $t$-test was used to calculate $p$ values of significance. Differences with $p$ values of $<0.05$ were considered significant.

\section{Results}

3.1. Characteristics of K18-hACE2 Mice Following SARS-CoV-2 Infection by the Intranasal Route

Six-week-old K18-hACE2 mice of both sexes were infected intranasally with PBS (mock, $n=10$ mice) or $10^{5}$ PFU of SARS-CoV-2 in PBS ( $n=20$ mice). The mock-infected mice remained healthy throughout the observation period. Virus infection resulted in $100 \%$ mortality by day 6 after infection (Figure 1A). Infected mice experienced significant weight loss on days 4 through 6 after infection compared to the mock-infected group (Figure 1B). Starting on day 4 , all the infected animals began to show signs of disease, such as lethargy, slow movement and labored breathing. Neurological symptoms such as hunchbacked posture, ruffled fur, tremors and ataxic gait were also observed in infected mice on days 5 and 6 after infection.

A

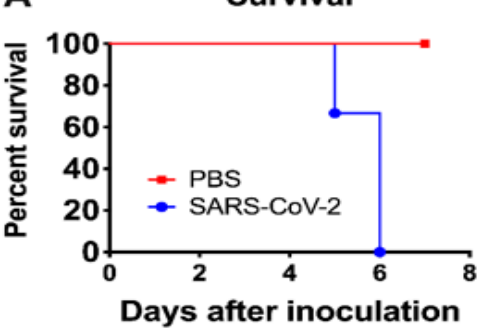

C Lung (Plaque Assay)

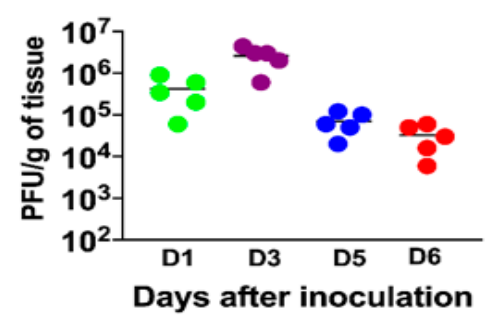

E Brain (Plaque assay)

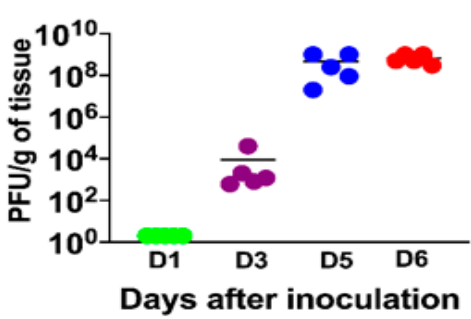

B Body Weight

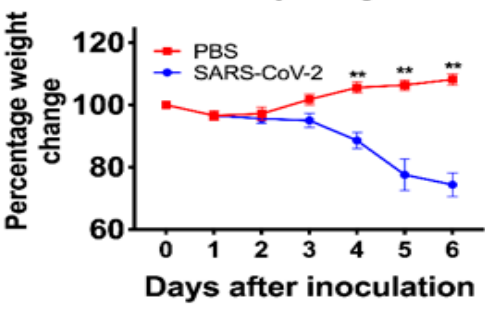

D Lung (RT-PCR)
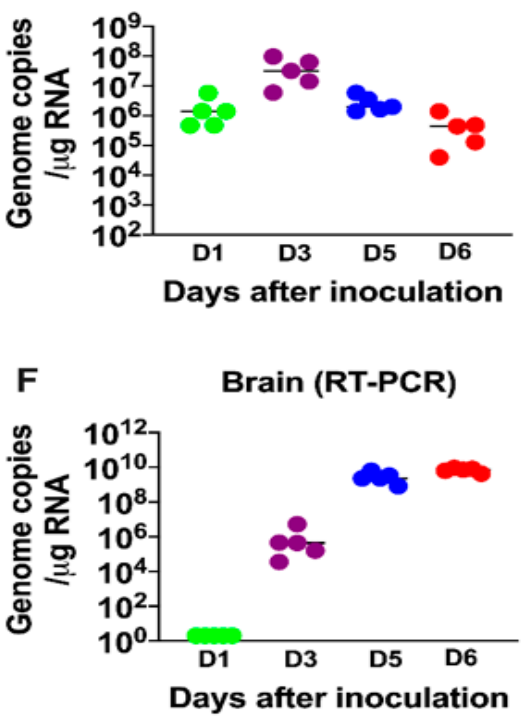

Figure 1. Analysis of survival, body weight and virus titers in K18-hACE2 mice following SARS-CoV2 infection. K18-hACE2 mice were inoculated intranasally with SARS-CoV-2 $\left(10^{5}\right.$ plaque-forming units (PFU), $(n=20)$ or PBS (Mock, $n=10)$. (A) Percentage of survival was determined. (B) Percentage of daily body weight change in the animals. Error bars represent SEM. ${ }^{* *}, p<0.001$. The kinetics and levels of SARS-CoV-2 were determined in the lungs $(\mathbf{C}, \mathbf{D})$ and brain $(\mathbf{E}, \mathbf{F})$ by plaque assay and qRT-PCR. The data are expressed as PFU/g of tissue or genome copies/ $\mu \mathrm{g}$ of RNA. Each data point represents an individual mouse. The solid horizontal lines signify the median value. 


\subsection{Virus Replication in the Periphery and Brains of K18-hACE2 Mice}

Six-week-old K18-hACE2 mice of both sexes were infected intranasally with PBS (mock, $n=12$ mice) or $10^{5}$ PFU of SARS-CoV-2 in PBS ( $n=20$ mice), and groups of 5 mice were used to measure the viral loads in the peripheral organs and brain at early (day 1), middle (day 3 ) and late (days 5 and 6) stages of infection. High virus levels were observed in the lungs on day 1, reached peak levels on day 3 and declined on days 5 and 6 after infection (Figure 1C,D). In contrast, virus was not detected in the brain on day one after infection, but was present by day 3. Very high levels of viral RNA and infectious virus were detected in the brains of all the animals by days 5 and 6 after infection (Figure 1E,F). The onset of neurological symptoms and mortality in infected mice correlated with peak virus titers in the brain.

The virus replication kinetics observed in the nasal turbinates was similar to those in the lungs, with the highest viral RNA levels detected during the early stage of infection (days 1 and 3), followed by a decline at later stages of infection (days 5 and 6) (Figure 2). In the olfactory bulbs and eyes, low levels of viral RNA were detected on days 1 and 3 after infection, with very high levels of viral RNA detected in all the animals on days 5 and 6 after infection, indicating productive infection within the olfactory system (Figure 2). By contrast, little if any virus was detected in the serum of infected mice at any time after infection.

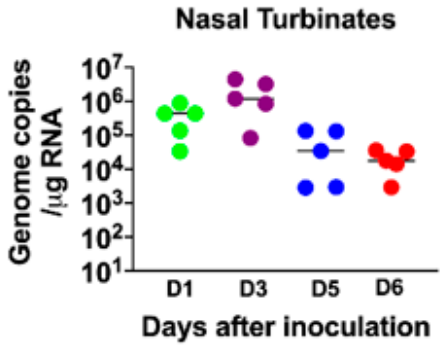

Serum
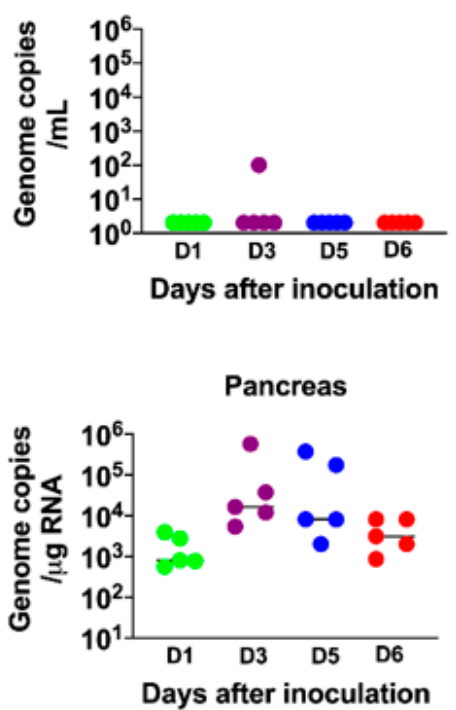

Olfactory bulbs

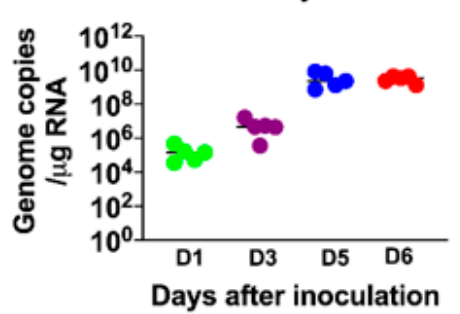

Kidney
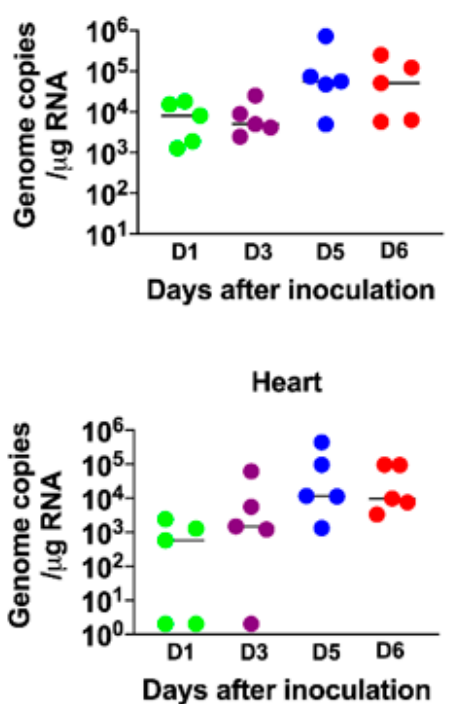

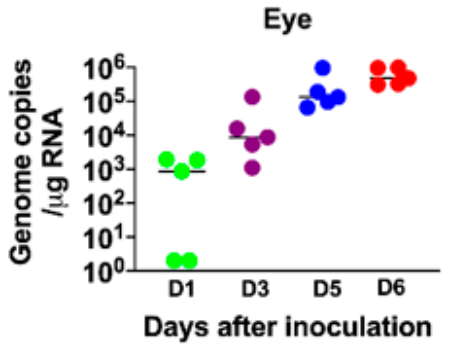

Spleen

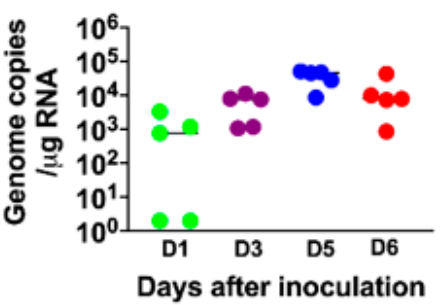

Liver

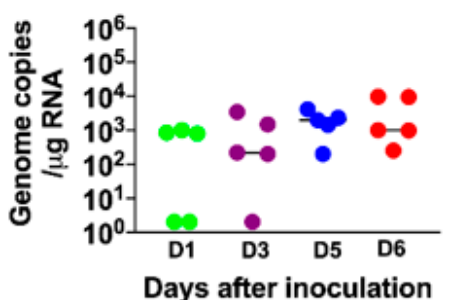

Figure 2. Analysis of virus tropism in K18-hACE2 mice. The viral RNA copy number in the nasal turbinates, olfactory bulbs, eye, serum, kidney, spleen, pancreas, heart and liver was determined on days 1, 3, 5 and 6 after infection by qRT-PCR and expressed as genome copies/ $\mu \mathrm{g}$ of RNA. Each data point represents an individual mouse. The solid horizontal lines signify the median value. 
Since the K18 promoter is known to be active in the epithelium of multiple organs of K18-hACE2 mice $[27,36]$, we also evaluated viral RNA levels in other peripheral organs. Viral RNA was detected in the heart, kidney, spleen, pancreas and liver on day 1 . There was a slight increase in RNA levels on day 3 and/or 5 in each of these organs, suggesting limited virus replication at these sites (Figure 2). These data agree with previous reports that also showed the presence of SARS-CoV-2 RNA in these organs [22-25,27,36].

\subsection{Inflammatory Changes in the Lungs and Brain of SARS-CoV-2-Infected Mice}

IFN signaling has a pivotal role in developing an innate and adaptive immune response to viral infection $[37,38]$. Therefore, we measured the mRNA and protein levels of IFN- $\alpha$ in the lungs and brain. In the lungs, an increase in both IFN- $\alpha$ mRNA and protein levels was detected on day 1 ; levels peaked at day 3 and then decreased on day 6 after infection (Figure 3A,B). By contrast, an IFN response was not detected in the brain on days 1 and 3 after infection. High levels of IFN- $\alpha$ were only detected in the brain on days 5 and 6 after infection (Figure 3C,D). Overall, the induction of IFN- $\alpha$ correlated with the SARS-CoV-2 replication kinetics in the lungs and brain. It is interesting to note that relative IFN- $\alpha$ levels were higher in the lungs compared to the brains of the infected animals despite higher virus replication in the brain.

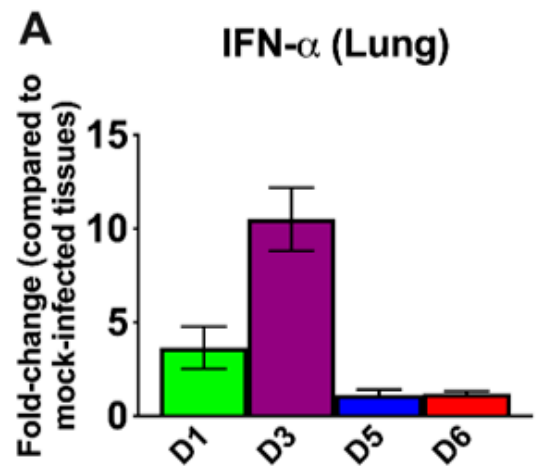

B IFN- $\alpha$ (Lung)
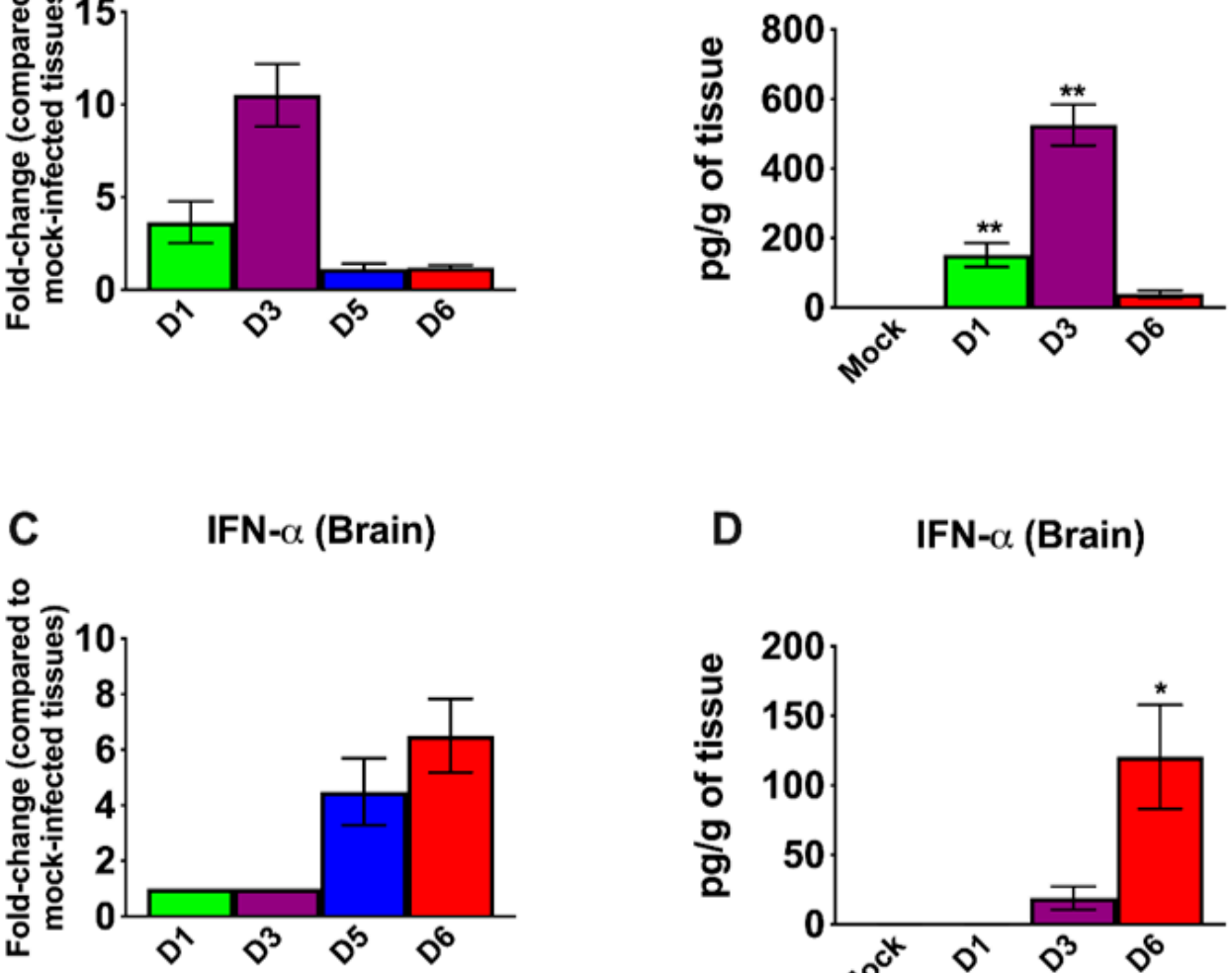

D IFN- $\alpha$ (Brain)

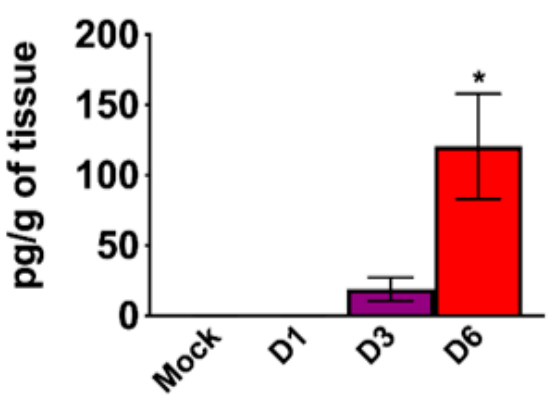

Figure 3. Analysis of mRNA and protein levels of interferon- $\alpha$ (IFN- $\alpha$ ) in the lungs and brain. The mRNA levels of IFN- $\alpha$ were measured in the lungs (A) and brain (C) by qRT-PCR, and the fold change in the infected tissues compared to the corresponding mock-infected controls was calculated after normalizing to GAPDH mRNA. The protein levels of IFN- $\alpha$ were measured in the lungs (B) and brain (D) homogenates using ELISA and expressed as pg/g of tissue. Error bars represent SEM ( $n=5$ mice per group). ${ }^{*} p<0.05 ;{ }^{* *} p<0.001$. 
We next examined the mRNA levels of proinflammatory cytokines and chemokines in the lungs and brain of infected mice. SARS-CoV-2 infection resulted in a 10-fold increase on day 1 and a 100-fold increase on day 3 in the interleukin (IL)-6 mRNA expression in the lungs (Figure $4 \mathrm{~A}$ ). The levels of TNF- $\alpha$ mRNA were elevated $\sim 10$-fold in the lungs on days 1 and 3 after infection. The level of IFN- $\gamma$ mRNA was elevated by 15 -fold on day 3 . However, the levels of these cytokines had decreased by day 5 after infection. The IL-1 $\beta$ mRNA levels showed no significant increase at any time point after infection. There was a 100 -fold increase in the expression of CCL2 on day 3 (Figure 4B). However, the levels of CCL2 mRNA had decreased by day 5 after infection. CCL3 mRNA levels increased slightly on day 1 and were undetectable on days 5 and 6 after infection.

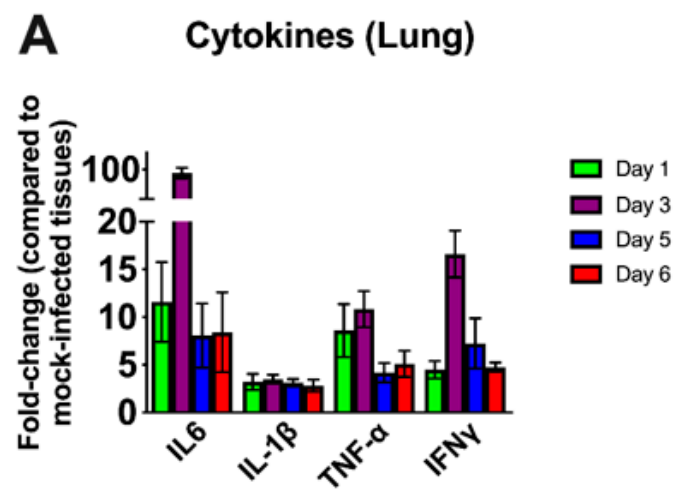

\section{B Chemokines (Lung)}
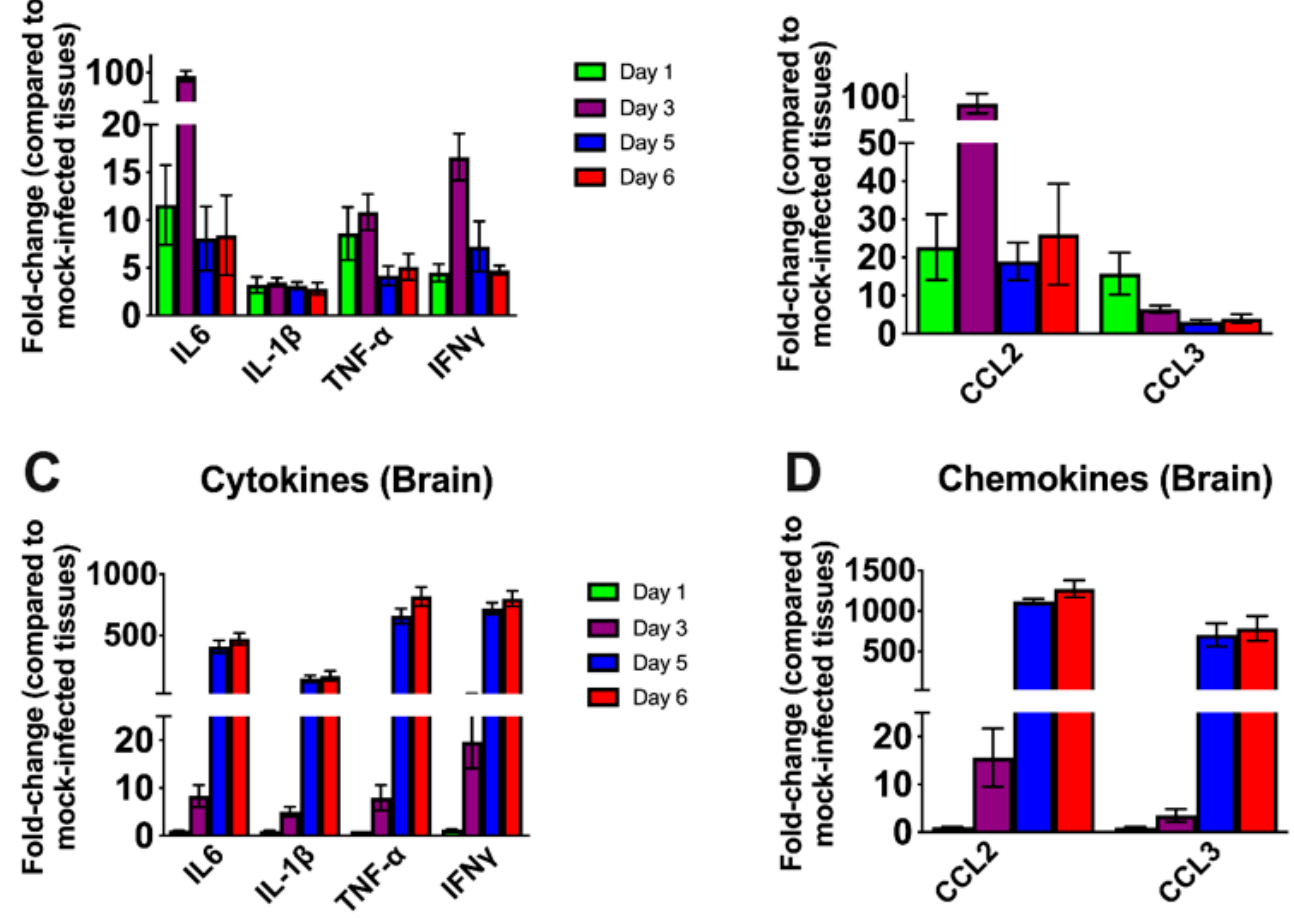

Figure 4. Cytokine and chemokine mRNA levels in the lungs and brain. The mRNA levels of various cytokine and chemokine genes were determined in the lungs $(\mathbf{A}, \mathbf{B})$ and brain $(\mathbf{C}, \mathbf{D})$ using qRT-PCR. Fold change in the infected tissues compared to the corresponding mock controls was calculated after normalizing to GAPDH mRNA in each sample. Error bars represent SEM ( $n=5$ mice per group).

In the brain, no increase in the mRNAs of the cytokines or chemokines tested was observed on day 1 after infection. Less than a 10-fold increase was observed in the cytokine mRNA levels on day 3 (Figure 4C). There was a 500-fold increase in IL-6 mRNA by day 5 after infection. TNF- $\alpha$ and IFN- $\gamma$ mRNA levels increased by $\sim 750$-fold in the brain by day 5 after infection. Similarly, IL-1 $\beta$ mRNA levels increased by 400 -fold by day 5 after infection. Both CCL2 and CCL3 mRNA levels were elevated by almost 1000-fold on days 5 and 6 after infection consistent with the high level of virus in the brain (Figure 4D). These results indicate that the inflammatory response was more pronounced in the brain than in the lungs at the later stage of infection.

\subsection{SARS-CoV-2-Induced Neuropathology in K18-hACE2 Mice}

We next analyzed the brain sections from infected mice for antigen distribution, infiltration of immune cells and cell death. Immunohistochemical staining for the SARS-CoV-2 spike protein detected cell-associated viral antigen throughout the brain on day 6 after infection. Representative data for sections from the cortex, cerebellum and hippocampus 
regions are shown in Figure 5. We also detected virus antigen in sections of the olfactory bulb of infected animals on day 6. H\&E staining of brain sections from the infected mice demonstrated perivascular hemorrhage and neuronal cell death (Figure 6A,B). The neurons of infected mice demonstrated a shrunken neuron body with light pink cytoplasmic staining, representing degenerating neurons (Figure 6B). Enhanced leukocyte infiltration was detected within blood vessel walls and in the perivascular space (Figure 6A). Evidence of leukocyte infiltration was confirmed by direct immunohistochemical analysis of the CD45 antigen, which revealed many CD45-positive cells in the brain parenchyma near neurons (Figure 6C). SARS-CoV-2-induced cell death was evaluated by direct TUNEL staining of brain tissues. On day 6, infected K18-hACE2 mice had elevated numbers of TUNELpositive cells in the cortex, hippocampus and cerebellum regions, indicating increased cell death (Figure 6D).

Mock
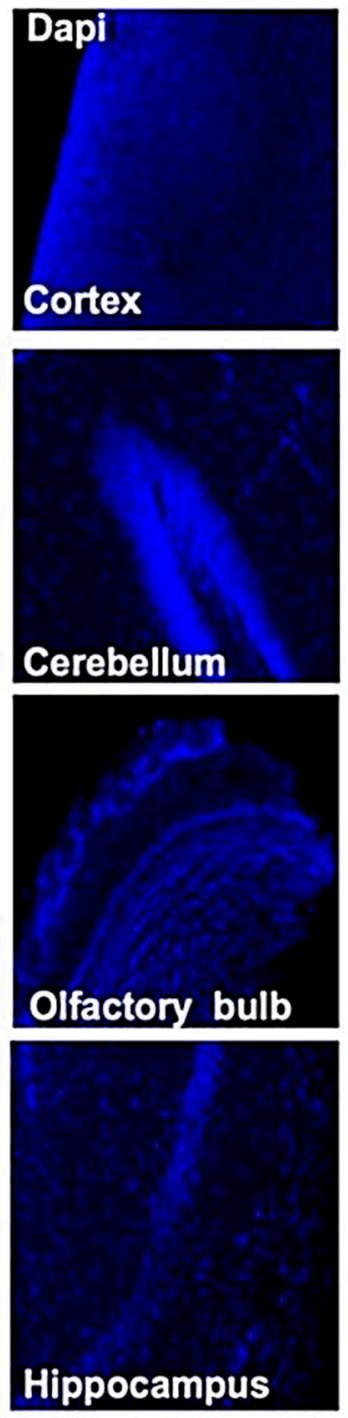
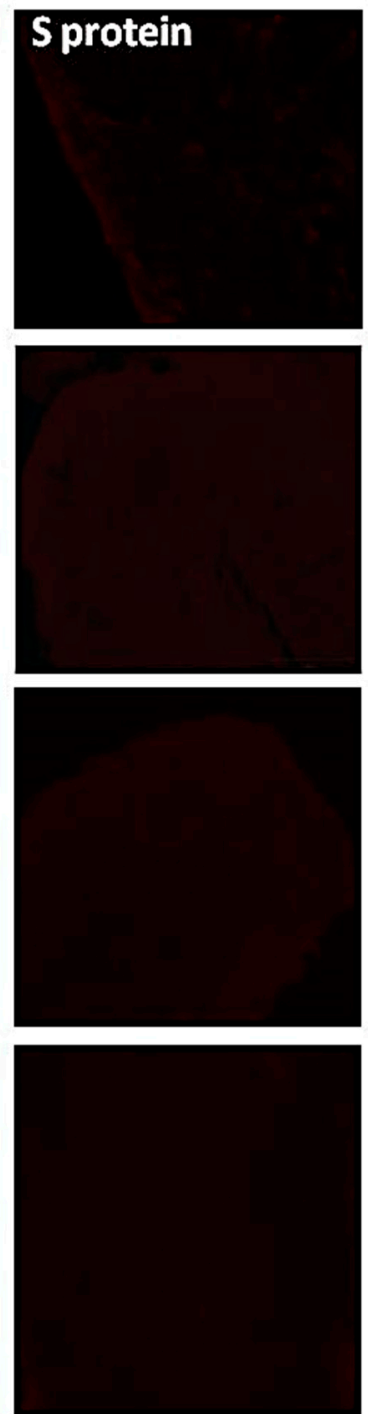

SARS-CoV-2
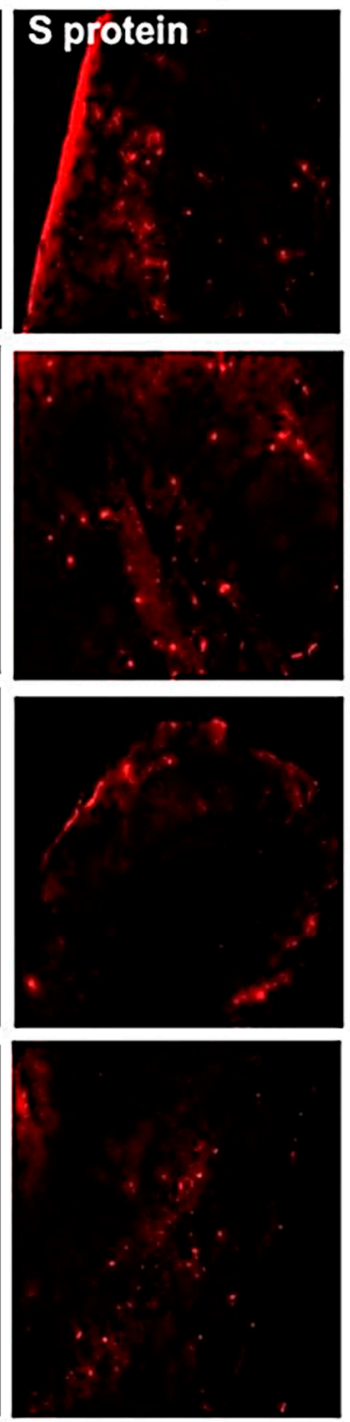

Figure 5. Detection of SARS-CoV-2-infected cells in the brains of K18-hACE2 transgenic mice. Brain sections (day 6 after infection) were stained for SARS-CoV-2 spike protein. Representative immunostaining images showing the presence of SARS-CoV-2 spike protein (red) in the cortex, cerebellum, hippocampus and olfactory bulb of infected mice. Nuclei were stained with 4',6-diamidino-2phenylindole (DAPI) (blue). The photomicrographs shown are representative of the images obtained from five animals. Bars, $20 \mu \mathrm{m}$. 

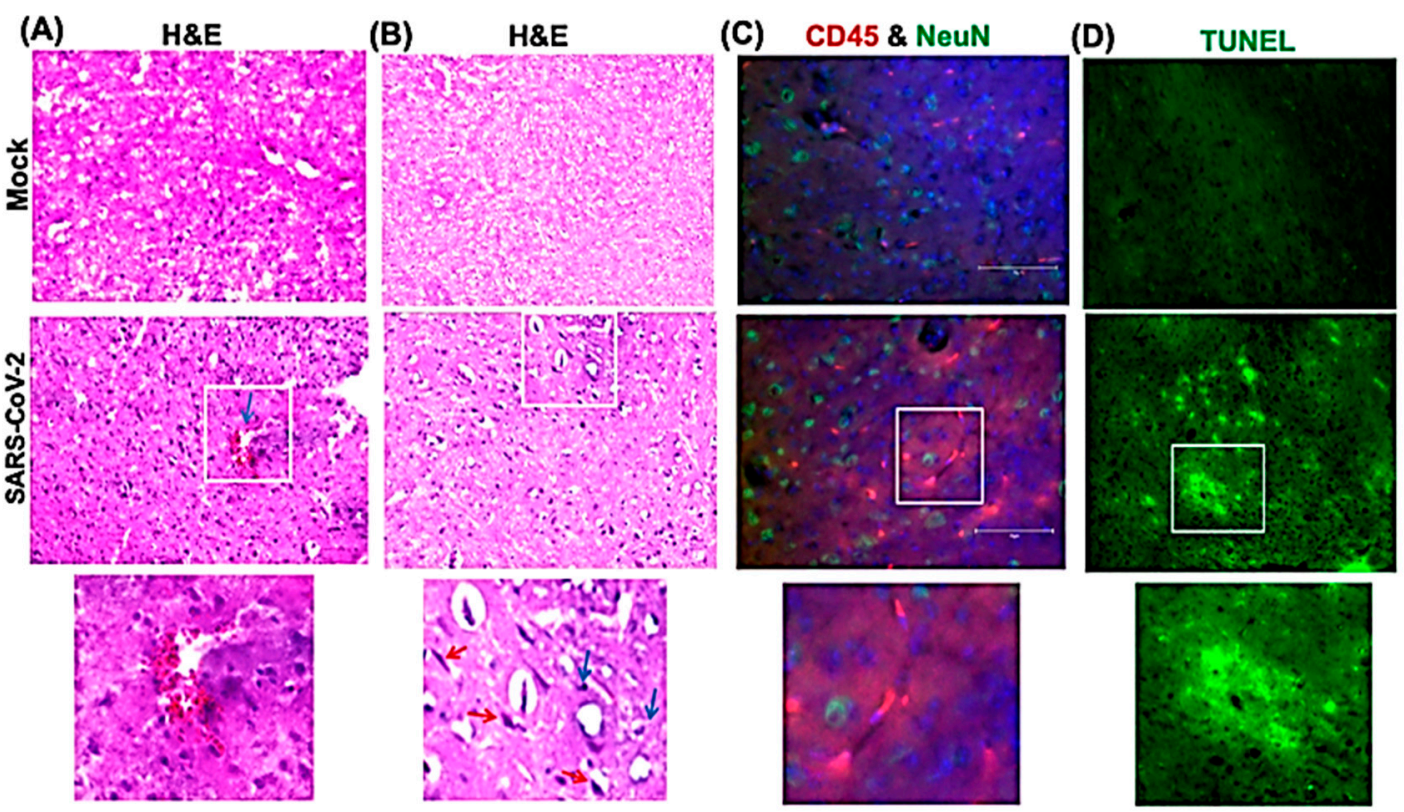

Figure 6. Histopathological analysis of SARS-CoV-2-infected brains. Hematoxylin and eosin (H\&E) staining of brain sections from mock and SARS-CoV-2-infected mice on day 6 after infection. (A,B) Brain sections show perivascular hemorrhage, enhanced leukocyte infiltration (blue arrows) and neuronal cell death (red arrows). (C) Brain sections are stained for CD45 (Red, leukocyte marker) and NeuN (Green, neuronal cell marker). Nuclei are stained with DAPI (blue). (D) A terminal deoxynucleotidyl transferase nick end labeling (TUNEL) assay was conducted on brain sections from mock and SARS-CoV-2-infected mice on day 6 after infection to detect apoptotic cells. The boxed areas in the second row of panels are enlarged in the bottom row of panels. The photomicrographs shown are representative of the images obtained from five animals. Bars, $20 \mu \mathrm{m}$.

\section{Discussion}

This study demonstrates a critical role of direct infection of CNS cells and of the inflammatory response in mediating SARS-CoV-2-induced lethal disease in K18-hACE2 mice. Intranasal inoculation of the virus results in a lethal disease with high levels of virus replication in the brain. Virus infection of the CNS was accompanied by an inflammatory response as indicated by the production of cytokines/chemokines, infiltration of leukocytes into the perivascular space and parenchyma and CNS cell death. Our data also indicate that following infection by the intranasal route, the virus enters the brain by traversing the cribriform plate and infecting neuronal processes located near the site of intranasal inoculation.

Some animal coronaviruses, such as MHV readily infect neurons and cause lethal encephalitis in mice $[11,39]$. SARS-CoV-1 infection also induces severe neurological disease after intranasal administration in K18-hACE2 mice [27]. Similarly, in our study, SARS$\mathrm{CoV}-2$ virus antigen was detected throughout the brain, including the cortex, cerebellum and hippocampus. The onset of severe disease in SARS-CoV-2-infected mice correlated with peak viral levels in the brain, immune cell infiltration and CNS cell death. Peak virus titers in the brains were approximately 1000 times higher than the peak titers in the lungs, suggesting a high replicative potential of SARS-CoV-2 in the brain. The relative upregulation of cytokine and chemokine mRNAs was approximately 10 to 50 times higher in the brain compared to the lungs, strongly suggesting that extensive neuroinflammation contributed to clinical disease in these mice.

It was recently reported that SARS-CoV-2 infection of K18-hACE2 mice causes severe pulmonary disease with high virus levels detected in the lungs of these mice and that mortality was due to the lung infection [22-25]. In these studies, viral RNA was undetectable in the brains of the majority of the infected animals, indicating a limited role of brain infection in disease induction. An important distinction between our study and 
others is that we detected high infectious virus titers in the olfactory system and brains of $100 \%$ of the infected K18-hACE2 mice. This phenotype was not consistently observed in the aforementioned K18-hACE2 mouse studies [22-25]. Moreover, none of the published studies evaluated the extent of neuroinflammation and neuropathology at the later stages of infection. Our results showed that the inflammatory response was more pronounced in the brain than in the lungs on days 5 and 6 after infection. Although both our study and the previous studies infected mice via the intranasal route, the other studies used older (7-to 9-week-old) K18-hACE2 mice and a lower viral dose ( $\left.10^{4} \mathrm{PFU}\right)$, and in one study, only analyzed samples 3 days after infection [22]. In our study, six-week-old K18-hACE2 mice were infected with $10^{5} \mathrm{PFU}$. However, unpublished data from our laboratory demonstrated that six-week-old K18-hACE2 mice infected with a lower viral dose ( $\left.10^{3} \mathrm{PFU}\right)$ also exhibit a similar phenotype, suggesting that the brain is a major site of infection following infection by the intranasal route, regardless of the virus dose used. Additional studies are needed to clarify the parameters that differentially affect tissue tropism, routes of virus dissemination and mechanisms of lung and brain injuries in K18-hACE2 mice following SARS-CoV-2 infection. Recent studies have suggested that humans have a higher chance of developing a brain infection if they are infected intranasally with a high dose of virus [40].

Alterations in smell and taste are features of COVID-19 disease in humans [8,41]. Pathological analyses of human COVID-19 autopsy tissues detected the presence of SARSCoV-2 proteins in endothelial cells within the olfactory bulb [41,42]. Our data indicate that SARS-CoV-2 can productively infect cells within the nasal turbinate, eye and olfactory bulb in intranasally infected K18-hACE2 mice. Virus infection of cells in these tissues in humans may explain the loss of smell associated with some COVID-19 cases [41]. The detection of virus replication in these tissues suggests that SARS-CoV-2 can access the brain by first infecting the olfactory bulb and then spreading into the brain by infecting connecting brain neuron axons. This hypothesis is consistent with previously published reports that neurotropic coronaviruses infect olfactory neurons and are transmitted to the brain via axonal transportation $[8,26,27,43]$. Many viruses, such as HSV-1, Nipah virus, rabies virus, Hendra virus and influenza A virus, have also been shown to enter the CNS via olfactory sensory neurons [44-47]. Another route by which a virus can gain access to the brain is via the disruption of the blood-brain barrier (BBB). However, we could not detect any virus in the serum of the infected mice at any time after infection, suggesting a limited role of BBB disruption in SARS-CoV-2 neuroinvasion. This finding is in agreement with previously published studies that detected little or no virus in the blood of K18-hACE2 mice after infection with SARS-CoV-1 or SARS-CoV-2 [22-25,27,36].

In summary, we found that intranasal infection of K18-hACE2 mice by SARS-CoV-2 causes severe neurological disease. Our data demonstrate that the CNS is the major target of SARS-CoV-2 infection in K18-hACE2 mice under the conditions used, and that brain infection leads to immune cell infiltration, inflammation and cell death.

Author Contributions: Conceptualization, M.K. and M.A.B.; methodology, P.K., J.P.N., H.A.R., S.S., K.A., P.G.S., H.P. and M.K.; validation, P.K., J.P.N., H.A.R., S.S. and M.K.; formal analysis, P.K., J.P.N., H.A.R., S.S., K.A. and M.A.B., M.K.; resources, M.K.; writing-original draft preparation, H.A.R., K.A. and M.K.; writing-review and editing, H.A.R., K.A., M.A.B. and M.K.; funding acquisition, M.K. and M.A.B. All authors have read and agreed to the published version of the manuscript.

Funding: This work was supported by a grant (R21NS099838) from the National Institute of Neurological Disorders and Stroke, a grant (R21OD024896) from the Office of the Director, National Institutes of Health, a grant from the Defense Advanced Research Projects Agency (HR00111920008), a grant (U19 AI131130) from the NIH, and Institutional funds.

Institutional Review Board Statement: Not applicable.

Informed Consent Statement: Not applicable.

Data Availability Statement: Not applicable. 
Acknowledgments: We thank members of the GSU High Containment Core and the Department for Animal Research for assistance with the experiments.

Conflicts of Interest: The authors declare no conflict of interest.

\section{References}

1. Rothan, H.A.; Byrareddy, S.N. The epidemiology and pathogenesis of coronavirus disease (COVID-19) outbreak. J. Autoimmun. 2020, 109, 102433. [CrossRef] [PubMed]

2. Rothan, H.A.; Acharya, A.; Reid, S.P.; Kumar, M.; Byrareddy, S.N. Molecular Aspects of COVID-19 Differential Pathogenesis. Pathogens 2020, 9, 538. [CrossRef] [PubMed]

3. Espinosa, P.S.; Rizvi, Z.; Sharma, P.; Hindi, F.; Filatov, A. Neurological Complications of Coronavirus Disease (COVID-19): Encephalopathy, MRI Brain and Cerebrospinal Fluid Findings: Case 2. Cureus 2020, 12, e7930. [CrossRef] [PubMed]

4. Filatov, A.; Sharma, P.; Hindi, F.; Espinosa, P.S. Neurological Complications of Coronavirus Disease (COVID-19): Encephalopathy. Cureus 2020, 12, e7352. [CrossRef] [PubMed]

5. Heneka, M.T.; Golenbock, D.; Latz, E.; Morgan, D.; Brown, R. Immediate and long-term consequences of COVID-19 infections for the development of neurological disease. Alzheimer's Res. Ther. 2020, 12, 69. [CrossRef]

6. Mahammedi, A.; Saba, L.; Vagal, A.; Leali, M.; Rossi, A.; Gaskill, M.; Sengupta, S.; Zhang, B.; Carriero, A.; Bachir, S.; et al. Imaging in Neurological Disease of Hospitalized COVID-19 Patients: An Italian Multicenter Retrospective Observational Study. Radiology 2020, 297, E270-E273. [CrossRef] [PubMed]

7. Parry, A.H.; Wani, A.H.; Yaseen, M. Neurological Dysfunction in Coronavirus Disease-19 (COVID-19). Acad. Radiol. 2020, 27, 1329-1330. [CrossRef]

8. Baig, A.M.; Sanders, E.C. Potential neuroinvasive pathways of SARS-CoV-2: Deciphering the spectrum of neurological deficit seen in coronavirus disease-2019 (COVID-19). J. Med. Virol. 2020, 92, 1845-1857. [CrossRef]

9. Adamczyk-Sowa, M.; Niedziela, N.; Kubicka-Baczyk, K.; Wierzbicki, K.; Jaroszewicz, J.; Sowa, P. Neurological symptoms as a clinical manifestation of COVID-19: Implications for internists. Polish Arch. Intern. Med. 2020. [CrossRef]

10. Wang, H.Y.; Li, X.L.; Yan, Z.R.; Sun, X.P.; Han, J.; Zhang, B.W. Potential neurological symptoms of COVID-19. Ther. Adv. Neurol. Disord. 2020, 13, 1756286420917830. [CrossRef]

11. Schaumburg, C.S.; Held, K.S.; Lane, T.E. Mouse hepatitis virus infection of the CNS: A model for defense, disease, and repair. Front. Biosci. 2008, 13, 4393-4406. [CrossRef] [PubMed]

12. Verstrepen, K.; Baisier, L.; De Cauwer, H. Neurological manifestations of COVID-19, SARS and MERS. Acta Neurol Belg. 2020, 120, 1051-1060. [CrossRef] [PubMed]

13. Lavoie, J.L.; Cassell, M.D.; Gross, K.W.; Sigmund, C.D. Adjacent expression of renin and angiotensinogen in the rostral ventrolateral medulla using a dual-reporter transgenic model. Hypertension 2004, 43, 1116-1119. [CrossRef] [PubMed]

14. Gowrisankar, Y.V.; Clark, M.A. Angiotensin II regulation of angiotensin-converting enzymes in spontaneously hypertensive rat primary astrocyte cultures. J. Neurochem. 2016, 138, 74-85. [CrossRef] [PubMed]

15. Lukiw, W.J.; Pogue, A.; Hill, J.M. SARS-CoV-2 Infectivity and Neurological Targets in the Brain. Cell. Mol. Neurobiol. 2020, 1-8. [CrossRef] [PubMed]

16. Puelles, V.G.; Lutgehetmann, M.; Lindenmeyer, M.T.; Sperhake, J.P.; Wong, M.N.; Allweiss, L.; Chilla, S.; Heinemann, A.; Wanner, N.; Liu, S.; et al. Multiorgan and Renal Tropism of SARS-CoV-2. N. Engl. J. Med. 2020, 383, 590-592. [CrossRef]

17. Solomon, I.H.; Normandin, E.; Bhattacharyya, S.; Mukerji, S.S.; Keller, K.; Ali, A.S.; Adams, G.; Hornick, J.L.; Padera, R.F., Jr.; Sabeti, P. Neuropathological Features of Covid-19. N. Engl. J. Med. 2020, 383, 989-992. [CrossRef]

18. Zhang, B.Z.; Chu, H.; Han, S.; Shuai, H.; Deng, J.; Hu, Y.F.; Gong, H.R.; Lee, A.C.; Zou, Z.; Yau, T.; et al. SARS-CoV-2 infects human neural progenitor cells and brain organoids. Cell Res. 2020, 30, 928-931. [CrossRef]

19. Ramani, A.; Muller, L.; Ostermann, P.N.; Gabriel, E.; Abida-Islam, P.; Muller-Schiffmann, A.; Mariappan, A.; Goureau, O.; Gruell, H.; Walker, A.; et al. SARS-CoV-2 targets neurons of 3D human brain organoids. EMBO J. 2020, 39, e106230. [CrossRef]

20. von Weyhern, C.H.; Kaufmann, I.; Neff, F.; Kremer, M. Early evidence of pronounced brain involvement in fatal COVID-19 outcomes. Lancet 2020, 395, e109. [CrossRef]

21. Cheng, Q.; Yang, Y.; Gao, J. Infectivity of human coronavirus in the brain. EBioMedicine 2020, 56, 102799. [CrossRef]

22. Golden, J.W.; Cline, C.R.; Zeng, X.; Garrison, A.R.; Carey, B.D.; Mucker, E.M.; White, L.E.; Shamblin, J.D.; Brocato, R.L.; Liu, J.; et al. Human angiotensin-converting enzyme 2 transgenic mice infected with SARS-CoV-2 develop severe and fatal respiratory disease. JCI Insight 2020, 5, e142032. [CrossRef] [PubMed]

23. Winkler, E.S.; Bailey, A.L.; Kafai, N.M.; Nair, S.; McCune, B.T.; Yu, J.; Fox, J.M.; Chen, R.E.; Earnest, J.T.; Keeler, S.P.; et al. SARS-CoV-2 infection of human ACE2-transgenic mice causes severe lung inflammation and impaired function. Nat. Immunol. 2020, 21, 1327-1335. [CrossRef] [PubMed]

24. Moreau, G.B.; Burgess, S.L.; Sturek, J.M.; Donlan, A.N.; Petri, W.A.; Mann, B.J. Evaluation of K18-hACE2 Mice as a Model of SARS-CoV-2 Infection. Am. J. Trop. Med. Hyg. 2020, 103, 1215-1219. [CrossRef] [PubMed]

25. Zheng, J.; Wong, L.R.; Li, K.; Verma, A.K.; Ortiz, M.; Wohlford-Lenane, C.; Leidinger, M.R.; Knudson, C.M.; Meyerholz, D.K.; McCray, P.B., Jr.; et al. COVID-19 treatments and pathogenesis including anosmia in K18-hACE2 mice. Nature 2020, 1-5. [CrossRef]

26. Perlman, S.; Evans, G.; Afifi, A. Effect of olfactory bulb ablation on spread of a neurotropic coronavirus into the mouse brain. $J$ Exp. Med. 1990, 172, 1127-1132. [CrossRef] 
27. Netland, J.; Meyerholz, D.K.; Moore, S.; Cassell, M.; Perlman, S. Severe acute respiratory syndrome coronavirus infection causes neuronal death in the absence of encephalitis in mice transgenic for human ACE2. J. Virol. 2008, 82, 7264-7275. [CrossRef]

28. Rothan, H.A.; Stone, S.; Natekar, J.; Kumari, P.; Arora, K.; Kumar, M. The FDA-approved gold drug auranofin inhibits novel coronavirus (SARS-COV-2) replication and attenuates inflammation in human cells. Virology 2020, 547, 7-11. [CrossRef]

29. Rothan, H.A.; Arora, K.; Natekar, J.P.; Strate, P.G.; Brinton, M.A.; Kumar, M. Z-DNA-Binding Protein 1 Is Critical for Controlling Virus Replication and Survival in West Nile Virus Encephalitis. Front. Microbiol. 2019, 10, 2089. [CrossRef]

30. Natekar, J.P.; Rothan, H.A.; Arora, K.; Strate, P.G.; Kumar, M. Cellular microRNA-155 Regulates Virus-Induced Inflammatory Response and Protects against Lethal West Nile Virus Infection. Viruses 2019, 12, 9. [CrossRef]

31. Kumar, M.; Roe, K.; Orillo, B.; Muruve, D.A.; Nerurkar, V.R.; Gale, M., Jr.; Verma, S. Inflammasome adaptor protein Apoptosisassociated speck-like protein containing CARD (ASC) is critical for the immune response and survival in west Nile virus encephalitis. J. Virol. 2013, 87, 3655-3667. [CrossRef] [PubMed]

32. Kumar, M.; Krause, K.K.; Azouz, F.; Nakano, E.; Nerurkar, V.R. A guinea pig model of Zika virus infection. Virol. J. 2017, 14, 75. [CrossRef] [PubMed]

33. Krause, K.; Azouz, F.; Nakano, E.; Nerurkar, V.R.; Kumar, M. Deletion of Pregnancy Zone Protein and Murinoglobulin-1 Restricts the Pathogenesis of West Nile Virus Infection in Mice. Front. Microbiol. 2019, 10, 259. [CrossRef] [PubMed]

34. Kumar, M.; Roe, K.; Nerurkar, P.V.; Orillo, B.; Thompson, K.S.; Verma, S.; Nerurkar, V.R. Reduced immune cell infiltration and increased pro-inflammatory mediators in the brain of Type 2 diabetic mouse model infected with West Nile virus. J. Neuroinflamm. 2014, 11, 80. [CrossRef]

35. Kumar, M.; Roe, K.; O'Connell, M.; Nerurkar, V.R. Induction of virus-specific effector immune cell response limits virus replication and severe disease in mice infected with non-lethal West Nile virus Eg101 strain. J. Neuroinflamm. 2015, 12, 178. [CrossRef]

36. McCray, P.B., Jr.; Pewe, L.; Wohlford-Lenane, C.; Hickey, M.; Manzel, L.; Shi, L.; Netland, J.; Jia, H.P.; Halabi, C.; Sigmund, C.D.; et al. Lethal infection of K18-hACE2 mice infected with severe acute respiratory syndrome coronavirus. J. Virol. 2007, 81, 813-821. [CrossRef]

37. tenOever, B.R. The Evolution of Antiviral Defense Systems. Cell Host Microbe 2016, 19, 142-149. [CrossRef]

38. Iwasaki, A.; Medzhitov, R. Regulation of adaptive immunity by the innate immune system. Science 2010, 327, 291-295. [CrossRef]

39. Roth-Cross, J.K.; Bender, S.J.; Weiss, S.R. Murine coronavirus mouse hepatitis virus is recognized by MDA5 and induces type I interferon in brain macrophages/microglia. J. Virol. 2008, 82, 9829-9838. [CrossRef]

40. Meinhardt, J.; Radke, J.; Dittmayer, C.; Franz, J.; Thomas, C.; Mothes, R.; Laue, M.; Schneider, J.; Brunink, S.; Greuel, S.; et al. Olfactory transmucosal SARS-CoV-2 invasion as a port of central nervous system entry in individuals with COVID-19. Nat. Neurosci. 2020, 1-8. [CrossRef]

41. Kanjanaumporn, J.; Aeumjaturapat, S.; Snidvongs, K.; Seresirikachorn, K.; Chusakul, S. Smell and taste dysfunction in patients with SARS-CoV-2 infection: A review of epidemiology, pathogenesis, prognosis, and treatment options. Asian Pac. J. Allergy Immunol. 2020, 38, 69-77. [CrossRef]

42. Cantuti-Castelvetri, L.; Ojha, R.; Pedro, L.D.; Djannatian, M.; Franz, J.; Kuivanen, S.; van der Meer, F.; Kallio, K.; Kaya, T.; Anastasina, M.; et al. Neuropilin-1 facilitates SARS-CoV-2 cell entry and infectivity. Science 2020, 370, 856-860. [CrossRef] [PubMed]

43. Dube, M.; Le Coupanec, A.; Wong, A.H.M.; Rini, J.M.; Desforges, M.; Talbot, P.J. Axonal Transport Enables Neuron-to-Neuron Propagation of Human Coronavirus OC43. J. Virol. 2018, 92, e00404-e00418. [CrossRef] [PubMed]

44. Swanson, P.A., 2nd; McGavern, D.B. Viral diseases of the central nervous system. Curr. Opin. Virol. 2015, 11, 44-54. [CrossRef] [PubMed]

45. van Riel, D.; Verdijk, R.; Kuiken, T. The olfactory nerve: A shortcut for influenza and other viral diseases into the central nervous system. J. Pathol. 2015, 235, 277-287. [CrossRef] [PubMed]

46. Blinzinger, K.; Anzil, A.P. Neural route of infection in viral diseases of the central nervous system. Lancet 1974, 2, 1374-1375. [CrossRef]

47. Durrant, D.M.; Ghosh, S.; Klein, R.S. The Olfactory Bulb: An Immunosensory Effector Organ during Neurotropic Viral Infections. ACS Chem. Neurosci. 2016, 7, 464-469. [CrossRef] 